\title{
A DESJUDICIALIZAÇÃO DA ALTERAÇÃO DO NOME E DO GÊNERO NO REGISTRO CIVIL DA PESSOA TRANSEXUAL
}

\begin{abstract}
This present work aims to analyses the recent process of non judicialization of changing name and gender in official state papers of transgender people in Brazil, made possible by the advent of the Supreme Court decisions, resulting from the Unconstitutionality Directive (ADI) 4275 and Provision $n^{\circ} 73$ from CNJ. To this end, 15 (fifteen) Natural Natural Person Registry Offices of the city of Recife were elected and delimited as the field of action of this study, seeking to demonstrate in practice the effects of living law. In this sense, the perspective with personality rights, sexual dignity, individual self-determination and the right to real truth will be approached as elements whose influence is intrinsic to the guarantee of fundamental rights that
\end{abstract}

guide the dignity of the human person. Moreover, within the precepts of a democratic and progressive society, it is clear that the maintenance of legal constraints that deprive the trans individual of living fully his right to identity.

Keywords: Dignity of the transgender person. Non Judicialization of name and gender. Body Self determination.

\section{Introdução}

Os movimentos
democratização
ampliação das esferas de debate sobre os
direitos das minorias emergiram a luta de
grupos minoritários que há muito
sofriam/sofrem diversos tipos de

\footnotetext{
${ }^{1}$ Pós-Doutor em Direito pela Università Degli Studi di Messina - Itália. Doutor em Direito pela Faculdade Autônoma de Direito de São Paulo - FADISP. Professor Adjunto da Universidade de Pernambuco - UPE. Professor Permanente do Programa de Pós-Graduação de Direitos Humanos - PPGDH da Universidade Federal de Pernambuco - UFPE. Pesquisador Visitante Sênior da Fiocruz - Piauí. giorgelando.gl@gmail.com

${ }^{2}$ Bacharela em Direito pela Universidade de Pernambuco - UPE, campus Benfica em Recife - PE. Perita Papiloscopista na Secretaria de Defesa Social do Estado de Pernambuco. robertalimasantos@gmail.com
} 
agressões aos seus direitos essenciais, através de decisões judiciais no sentido de perpetuação de preconceitos e negativas de direitos. Porquanto, qualquer outra forma de percepção que fuja ao majoritário social, sendo esse estruturado pela heterossexualidade normativa, tende a sofrer os mais diversos tipos de preconceitos e estigmas. Nessa esteira, a causa das pessoas trans, dentro do dinâmico universo dos LGBTQI+, mostra como a efetivação de direitos pode ser cerceada por uma cultura essencialmente heteronormativa, tal qual é a conservadora sociedade brasileira.

Assim, considerando esse panorama, a discussão que esse trabalho pretende trazer refere-se à análise do processo de desjudicialização da alteração do prenome e do gênero nos Registros Civis da pessoa transgênero, especialmente, analisando os efeitos desse fenômeno nos Cartórios de Registro de Pessoas Naturais da cidade do Recife/PE, depois da adoção do Provimento CNJ no 73/2018 e decisão histórica do Supremo Tribunal Federal STF sobre Ação Direta de Inconstitucionalidade - ADI 4275/2009.
Para tanto, este trabalho utilizou a metodologia de análise dos dados qualiquantitativos, tendo sido coletados através de informações enviadas pelos Cartórios de Recife, autorizados pela Corregedoria Auxiliar dos Serviços Notariais e de Registro da Capital do Poder Judiciário de Pernambuco. Também, foi aplicada a técnica de revisão bibliográfica de pertinência temática, a qual corroborou de maneira holística para avaliação qualitativa dos dados supracitados. Seguindo, no primeiro capítulo foram abordados retrospectos históricos da despatologização das pessoas trans, assim como sexualidade, construção de gênero e dignidade da pessoa.

Já o segundo capítulo, trouxe à tona temas como autonomia privada e autodeterminação corporal dentro do direito brasileiro, perpassando pelas cirurgias de redesignação, além de breve retrospecto de decisões judiciais a respeito do tema.

Por último, o terceiro capítulo tratou do direito à identidade e da extrajudicialização da alteração do nome e gênero, como também, foram apresentados os dados que motivaram a realização do presente trabalho. 


\section{Despatologização \\ da \\ pessoa \\ transgenêro}

As questões que envolvem transgêneros sempre suscitaram muitos questionamentos e polêmicas a cerca dos seus direitos, bem como, por muito tempo, sofreram sob o pesado estigma de terem sua condição identitária coligada a possíveis transtornos psíquicos ou de imagem. De acordo com Castel (2001, p. 80), o histórico da patologização da transexualidade pode ser divido em 04 (quatro) fases.

A primeira delas remonta às origens da sexologia, tendo por um dos expoentes o sexólogo Magnus Hirschfeld, um dos primeiros pesquisadores que iniciou estudos científicos em prol da despenalização da homossexualidade, nos primórdios do século XX (CASTEL, 2001, p. 80).

Já a segunda fase, caracterizouse pelo veloz desenvolvimento médico e científico, sendo eles catalisados pelos eventos da Segunda Guerra Mundial, ainda em consonância com Castel (2001, p. 86), os quais permitiram o desenvolvimento de técnicas com aplicação de hormônios e cirurgias estéticas.

Quanto a terceira fase, para o mesmo autor, vai do final da Segunda Guerra até meados dos anos 60, engloba um período de inúmeros eventos que contribuíram para a medicalização dos transexuais à força, a exemplo do caso Jorgensen, ex-soldado americano que submeteu-se a cirurgia de mudança de sexo bem sucedida da história, transformado em Christine, em 1952 (CASTEL, 2001). Nesta senda, de acordo com Arán e Murta (2009, p. 24), a cerca desse evento, dispõem que

A cirurgia realizada em Georges Jorgensen, que se tornou Christine em 1952, foi um marco para a definição da experiência da transexualidade tal como a compreendermos hoje. A midiatização da história de Jorgensen, operado por Christian Hamburger na Dinamarca e posteriormente atendido por Harry Benjamin nos Estados Unidos, vai contribuir enormemente para a reflexão sociológica sobre a identidade sexual e a construção da categoria de gênero.

[...] este caso ilumina um conjunto de acontecimentos que revolucionou a forma de compreender a relação entre sexo e gênero no âmbito científico.

O caso de Christine, acima supracitado, relembra a história do livro "A Garota Dinamarquesa", de David Ebershoff, que deu origem ao filme, no 
qual retratou a primeira cirurgia de mudança de sexo, não bem sucedida, da história. Segundo Soalheiro e Cançado (2017, p. 02), a história retrata os percalços da personagem principal em busca da sua identidade corporal durante a década de 20, do século passado. Contudo, a personagem encontra muitos estigmas e violência em decorrência da sua condição de trans, inclusive o diagnóstico de esquizofrenia, até chegar ao procedimento cirúrgico, o qual "contribuiu para o fortalecimento da identificação de Lili”.

Os casos descritos acima despertaram interesse da comunidade científica, tendo no endocrinologista Harry Benjamin um expoente na busca de justificavas científicas que determinassem as diferenças entre os transexuais e os homossexuais. Segundo os primeiros estudos desenvolvidos sobre a temática, existiria nos transexuais uma relação de abjeção com seus respectivos órgãos genitais, fato esse que impulsionou a Benjamim defender como única forma terapêutica, a cirurgia de transgenitalização, o que mais tarde seria comprovado que a referida abjeção não é regra para todas as pessoas trans (BENTO; PELÚCIO,
2012). Enquanto os homossexuais teriam apenas a inclinação sexual para o mesmo sexo pertencente, sem problemas de abjeção de aparência ou gênero. Ainda dentro dessa temática, conforme os mesmos autores:

$\mathrm{O}$ critério fundamental para definir o "transexual de verdade" seria a relação de abjeção, de longa duração, com suas genitálias. Para evitar que cometam suicídio, as cirurgias deveriam ser recomendadas a partir de um rol de procedimentos arrolados por Benjamin em sua obra (BENTO; PELÚCIO, 2012, p. 571).

Vale ressaltar que, durante esse percurso científico, houve a contraposição dos profissionais de psicanálise, psiquiatria e psicologia, visto que estes defendiam medidas terapêuticas ao invés do procedimento cirúrgico definitivo. No entanto, Benjamin continuou a insistir no método cirúrgico como única via para solucionar as ditas "enfermidades" dos considerados transexuais. É oportuno frisar que, ainda não existia nessa época a perspectiva dos transgêneros. Ainda, no ano de 1955, surge a primeira menção do conceito de gênero por John Money, após a ideia do "papel" aplicado a diferença dos sexos na sociedade, fato esse que daria gatilho para os eventos que seguiriam (CASTEL, 2001, p. 96). 
Por fim, a quarta fase tem inicio em meados dos anos 60 a 70, sendo esse período fomentado por fortes revoluções sociais, a exemplo das reivindicações de uma sexualidade libertária, em contraponto aos tradicionais códigos de comportamento social, o surgimento da pílula anticoncepcional, e o surgimento de nomes importantes dentro do ativismo em favor dos direitos homoafetivos, a exemplo de Harvey Milk, primeiro politico eleito declarado gay na Califórnia, e Marsha P. Johnson, trans que lutou nos Estados Unidos pelos direitos do público LGBTQI+ (Lésbicas, Gays, Bissexuais, Transgênero, Transexuais, Queer, Interssexuais e outros).

Nos anos que se seguiram, tais processos de definição científica levaram a transexualidade ao quadro de doenças mentais como "Transtorno de Identidade", tendo por marco os anos 1980, com a inclusão no Manual Diagnostico e Estatístico de Transtornos Mentais (DSM-IV), sob coordenação da Associação de Psiquiatria Norte Americana, conjuntamente com a influência do culturalismo à época, marcado por forte repressão moral e social. Segundo Bento e Pelúcio (2012) nesse documento poderiam ser identificadas as bases do chamado disforismo de gênero, conforme transcrição a seguir:

As performances de gênero, a sexualidade e a subjetividade são níveis constitutivos da identidade do sujeito que se apresentam colados uns aos outros. $\mathrm{O}$ masculino e o feminino só se encontram por intermédio da complementaridade da heterossexualidade. Quando há qualquer nível de descolamento, deve haver uma intervenção especializada, principalmente de algum especialista nas ciências psi, para restabelecer a ordem e a "coerência" entre corpo, gênero e sexualidade. É esse mapa que fornecerá as bases fundamentais para a construção do diagnóstico de gênero (BENTO; PELÚCIO, 2012, p. 571).

$\mathrm{Na}$ esteira desses acontecimentos, em 1992, a Organização Mundial da Saúde (OMS) libera a nova edição da Classificação Internacional de Doenças e Problemas de Saúde (CID), conhecida por CID-10, na qual, conforme lição de Bento e Pelúcio (2012, p. 572) seria uma “convenção médica que estabelece as características das doenças e seus respectivos códigos utilizados e aceitos internacionalmente por médicos/as e outros/as operadores/as da saúde".

Eis aqui o arcabouço histórico para o estigma da patologização das 
pessoas consideradas trans. Outro ponto importante, durante toda a formação dos preconceitos contra as minorias LGBTQI+, seria, também, a eclosão da epidemia de AIDS, a qual atingiu com maior força a esse grupo em meados dos anos 80. Assim, conforme palavras de Fábio (2017):

Homossexuais ganharam um novo estigma, como vetores de uma doença mortífera, e a pauta da liberação sexual se esvaziou frente à nova crise de saúde pública. Militantes do Estado de São Paulo, especialmente, deixaram os grupos estabelecidos. Muitos passaram a atuar em projetos de combate à Aids.

Diante de toda essa perspectiva histórica, foi ofertado um campo para o desenvolvimento do transgenerismo, quando o ponto crucial não seria mais a oferta do acesso a redefinição sexual pela medicina, mas, sim, a luta por direitos e diminuição das desigualdades sociais que continuam a afetar essa minoria social. Assim, de acordo com Castel (2001, p. 91), o "Transgenerismo tornouse pouco a pouco um movimento libertário com vastas ramificações", tendo aqui os primeiros questionamentos a cerca da real necessidade de submissão a uma cirurgia mutiladora para o adequamento em estereótipos de gênero.
Logo, tem espaço para uma visão pósmoderna sobre a construção do gênero.

Quando se observa a realidade brasileira, desde a edição do Código Penal de 1830, nunca existiu nenhuma lei que restringisse a homossexualidade. No entanto, foi considerada um comportamento social "desviante", bem como, até meados da década de 1980, era considerada doença e contava com o enquadramento tanto no Código de saúde do Instituto Nacional de Assistência Médica e Previdência Social Brasileira, quanto na Organização Mundial de Saúde - OMS. Ainda, conforme Fábio (2017) a despatologização da homossexualidade veio em 1985 com o aval do Conselho Federal de Medicina Brasileiro - CFM, antecedendo em 05 (cinco) anos as mudanças ocorridas na OMS. Em contrapartida, infere-se que os transgêneros permaneceram rotulados pela patologia de "transtorno sexual".

Durante a Constituinte de 1987, prosseguindo de acordo o autor supramencionado, diversos grupos LGBTQI+, a exemplo do grupo carioca “Triângulo Rosa", realizaram manifestações em defesa da inclusão do termo "orientação sexual" no rol dos 
objetivos da República, elencados no artigo $3^{\circ}$ da $\mathrm{CF} / 88$, onde estão expressos "origem, raça, sexo, cor e idade", para que, assim, garantisse a esses grupos proteção constitucional contra exclusão social por sua respectiva condição sexual. No entanto, devido as pressões de setores conservadores a época, tal tutela não foi permitida existir de forma expressa na Constituição Brasileira (FÁBIO, 2017). Insta frisar que, essa proteção constitucional só ocorreu em junho de 2019, quando o STF, através de decisão hermenêutica constitucional, decidiu a cerca o Mandado de Injunção 4733, no qual estendeu a qualificação como sendo crime de racismo a homotransfobia, e até que norma regulamentadora - lei - sobrevenha e legisle especificamente sobre o tema.

Especificamente, com relação aos transgêneros, o grande divisor de águas veio através da decisão da $\mathrm{ADI} \mathrm{n}^{\circ}$ 4.275/DF, ajuizada pela Procuradoria Geral da República (PGR), quando da decisão do STF pela possibilidade de alteração do nome e gênero no assento do Registro Civil de Pessoa Natural RCPN extrajudicialmente. Logo, confirmou-se a desnecessidade de jurisdição voluntária ou comprovação de realização de procedimento cirúrgico de redesignação de sexo para efetivação dos direitos civis da população transgênero brasileira.

\section{Sobre sexualidade e dignidade da pessoa transgênero}

A sexualidade é um termo abrangente, que engloba diversificados fatores. Logo, dificilmente caberia alguma definição que sintetizasse o que propriamente significa. Sobre a sexualidade humana, Bergesch e Chemin (2009, p. 10) dispõem que:

Ultrapassa a esfera biológica, a
mera função reprodutora da
espécie e a manifestação da libido
e do impulso sexual para a
satisfação carnal. Afirma este
autor que o homem, como ser, é
bipolar, apresentando dois sexos
distintos: um homem e uma
mulher. A definitiva distinção, de
acordo com os avanços dos
estudos da Biologia e da
Psicologia tem consentido a ideia
de que a masculinidade e a
feminilidade não são consideradas
valores opostos, mas graus
sucessivos de desenvolvimento da
sexualidade.

No entanto, importa frisar que sexualidade não se confunde com sexo, assim, têm-se a acepção por sexo uma determinação biológica fenotípica, quando conjunções hormonais e físicas confluirão para o enquadramento em 
determinado polo sexual, seja masculino ou feminino. Indo além, para Araújo (2016, p. 257), a ideia de sexo possui os diversos significados, que são:

[...] os principais sentidos são
aqueles ligados (1) à acepção
biológica (na distinção entre
macho e fêmea), (2) à ideia
classificatória (quanto r ao
"conjunto das pessoas que
possuem o mesmo sexo"), (3)
como sinônimo de sexualidade e
(4) como referencia aos órgãos
genitais externos.

Eis aqui o que se pode chamar de definições cunhadas pelo "gênero aparente", qual seja, aquele que se baseia por característica fenotípicas para a formação de um enquadramento sectário.

Já a sexualidade tem caráter intrínseco a compleitude da condição humana, logo, um ser humano só terá plenitude de gozo de sua dignidade quando o direito a sua sexualidade for resguardado e puder ele exerce-lo livremente. Ainda nas palavras de Araújo (2016, p. 259), "ninguém pode se realizar como ser humano sem ter assegurado o respeito ao exercício da sua sexualidade - conceito que compreende tanto a liberdade sexual como a liberdade à orientação sexual e a sua expressão".

$$
\text { Nessa senda, a Comissão }
$$

Especial de Diversidade Sexual da
Ordem dos Advogados do Brasil (OAB) elaborou as seguintes conceituações a respeito das diferenças entre gênero e sexo em uma Nota Técnica publicada no ano de 2014, as quais seguem listadas a seguir:

$\begin{aligned} & \text { Gênero é elemento subjetivo } \\ & \text { constituído por aspectos }\end{aligned}$
psicológicos, sociais e culturais
relativos aos padrões de
comportamentos definidos pela
prática cultural na qual as pessoas
vivem papéis estereotipadamente
masculinos e femininos;
Sexo é elemento biológico e
objetivamente aferível, ressalvado
o sexo civil, conceito jurídico que
pode não coincidir com o gênero
(OAB/2014) (grifo nosso).

Desta maneira, diante do exposto, percebe-se que a identidade de gênero não é um conceito definido, visto a culturalidade que o reveste, portanto, é passível de constantes transformações, principalmente, sendo elas provenientes da esfera social. Por isso, primeiramente, faz-se necessário compreender que quando se fala sobre o conceito de gênero, faz-se importante destacar que ele parte de uma construção social permeada por padrões comportamentais, ou seja, "gênero e sexualidade são construídos performativamente pela cultura ao longo do tempo e em diferentes contextos sociais que não são 
somente normativos" (FREITAS, 2016, p. 228).

Porquanto, qualquer outra forma de percepção que fuja ao majoritário social, sendo esse estruturado pela heterossexualidade normativa, tende a sofrer dos mais diversos tipos de preconceito e estigmas (SOALHEIRO; CANÇADO, 2017, p. 12). Além do mais, importa frisar que gênero não se confunde com orientação sexual, visto que a designação do sexo ao nascer, possui um caráter eminentemente biológico, ou seja, desconsideram-se componentes culturais, sociológicos, psicológicos e de outras ordens que serão essenciais para a construção da personalidade de cada ser humano (PONTES; SARAIVA, 2017, p. 85).

Infere-se assim, conforme os ensinamentos de Araújo (2016, p. 263), que "nem a homossexualidade nem a heterossexualidade são as únicas formas de expressão da sexualidade humanas". Dessa forma, a identidade do transgênero faz parte de uma construção oriunda do sentimento de pertencimento cultural e social a determinados padrões estéticos ou comportamentais considerados pertencentes ao sexo oposto à pessoa trans. Importa dizer que, quando uma pessoa se reconhece transgênero não significa dizer que há um desejo eminente de redesignação sexual. E vai além, nem mesmo é possível determinar que a pessoas trans terão atração sexual por pessoas do mesmo sexo, porquanto, reflete-se a existência de um conflito natural de identidade - em seu sentido amplo de reconhecimento e pertencimento - com o gênero, biologicamente falando.

Além do mais, segundo Butler (2003, p. 25) os seres humanos vão sendo moldados paralelamente às transformações sociais dos elementos socionormativos que os compõem, por conseguinte, "o gênero não deve ser meramente concebido como a inscrição cultural de significado num sexo previamente dado (concepção jurídica)".

\section{A mudança de paradigma: desobrigatoriedade da cirurgia de redesignação sexual}

Nessa senda, a OMS até bem pouco tempo considerava a transexualidade como transtorno mental, no entanto, em recente decisão, no ano de 2018 e, oficializada em 21 de maio de 2019, durante a $72^{\circ}$ Assembleia Mundial 
da Saúde, realizada em Genebra, foi retirada da Classificação Internacional de Doenças e Problemas de Saúde (CID). Dessa forma, a nova edição da CID-11, após longos 28 anos, a transexualidade deixou o rol de transtornos mentais e passou a integrar a categoria de Condições Relacionadas à Saúde Sexual, tendo sido classificada como incongruência de gênero.

Nesse interim, cumpre dizer que antes mesmo dessa abertura de paradigma por parte da OMS, o Conselho Federal de Psicologia (CFP) publicou no Brasil, em 29 de janeiro de 2018, a Resolução CFP n ${ }^{\circ}$ 01/2018, a qual trouxe a orientação aos profissionais de psicologia, direcionando suas respectivas atuações profissionais no sentido de não mais considerar por patologia a transexualidade. Ainda, é importante trazer os 03 (três) pilares nos quais estão alicerçadas as diretrizes da Resolução mencionada, que são: transexualidade e travestibilidade não são patologias; a transfobia precisa ser enfrentada; e as identidades de gênero são autodeclaratórias.

Retrocedendo na linha do tempo, no ano de 1999, foi aprovada e publicada pela Associação Mundial para a Saúde Sexual, a Declaração dos Direitos Sexuais, na qual foram estabelecidas diretrizes que englobaram a proteção e promoção dos direitos sexuais como sendo parte intrínseca dos Direitos Humanos Universais. Nesse sentido, tem-se por direitos sexuais como direitos inerentes aos conceitos de liberdade, dignidade e igualdade, por isso, a temática a cerca de saúde sexual possui profundo impacto no campo jurídico e social.

Diante dessa perspectiva, dentre as muitas diretrizes elencadas na Declaração supracitada, está o Direito a Autonomia e Integridade Corporal, o qual traz a concepção de que todos tem direito de controlar e decidir livremente a cerca de pontos relativos à sexualidade e seus corpos. Por conseguinte, inclui a liberdade de tomada de decisões de natureza sexual ou relativas ao próprio corpo, desta maneira, aqui insere-se as cirurgias de transgenitalização, popularmente conhecidas por cirurgias de mudança de sexo.

$$
\text { Analisando os eventos }
$$
expostos, tem-se a percepção de uma sistemática e vagarosa desconstrução da patologização que por muito tempo rotulou e estigmatizou a pessoa 
transgênero. Assim, reforçando tal ideia, pode-se dizer que até bem pouco tempo muitos tribunais condicionavam a modificação do nome e do gênero no Registro Civil apenas para aqueles que se submetessem a tratamentos hormonais e a cirurgia de mudança de sexo. Assim, eis aqui o ponto primordial do direito a autodeterminação e autonomia da esfera privada: cabe ao Estado regular ou judicar aspectos relativos à vida privada e formação de identidade? Qual dos bens são mais caros à sociedade plural e garantidora da dignidade humana, conforme prevê a Constituição Federal, a manutenção do nome e gênero segundo a linha biológica ou a permissão para que qualquer adulto capaz possa ter a liberdade de se auto definir conforme sua predisposição identitária?

Diante de toda essa conjuntura, fica demonstrado que a preservação da dignidade da pessoa transgênero não se baseia na adequação a sociedade heteronormativa, mas, sim, a garantia a autoderminação sexual e pleno gozo de sua autonomia privada dentro do campo social e legal. Nesse sentido, conforme as digressões de Costa e Campello (2017, p. 113) “o exercício da democracia está umbilicalmente ligado à consideração de todas as formas de existência em um país, livres de preconceitos, ao passo que garantir o bem de todos independentemente de estigmas é objetivo fundamental da República”. Por isso, fez-se necessário ressalvar o retrospecto de despatologização da pessoa transgênero e a construção de um arcabouço, neste trabalho, que demonstre a desnecessidade de imposição da cirurgia de mudança de sexo como única forma de modificação do nome e genro da pessoa trans.

\section{Autonomia privada e direito civil brasileiro: um olhar sobre a autodeterminação da pessoa trans}

Ao longo da história, muitos foram os questionamentos e obstáculos que a comunidade trans teve que superar para conseguiram galgar até as conquistas que hoje vivenciam, dentre elas, o objeto de pesquisa deste presente trabalho, que foi, o direito de alteração extrajudicial do nome e gênero no Registro Civil. Diante das transformações do direito a partir do viés constitucional, tem-se, assim, uma nova compreensão de autodeterminação do 
indivíduo, definida como elemento fundamental para assegurar a qualidade de vida e essencial à defesa das garantias das liberdades pessoais e dignidade dentro da perspectiva de uma sociedade plural. Ainda, para Fachin (2014, p. 37), "autodeterminar-se não significa agir irresponsavelmente, mas sim, exercer as liberdades pessoais do modo mais amplo possível, seja produzindo escolhas, seja criando uma identidade própria ou mesmo tomando decisões quanto ao próprio corpo."

Destarte, etimologicamente falando, a autodeterminação está incluída na esfera dos princípios mais caros aos direitos da dignidade da pessoa humana, abrangendo temas como autonomia, exercício de liberdades pessoais, livre-arbítrio, o que resulta numa confluência que permite a criação de uma identidade própria a respeito do próprio corpo. Assim, dentro desse panorama, felizes foram as palavras da ministra Carmen Lucia, a qual teceu o seguinte comentário a respeito da temática: "O Estado há que registrar o que a pessoa é, e não o que acha que cada um de nós deveria ser, segundo a sua conveniência” (BRASIL, 2018).
26

Dentro do conceito de identidade, tem-se o cenário, conforme os ensinamentos de Fachin (2014, p. 37), da identidade pessoal, na qual estão englobados aspectos como o direito de 'ser', bem como o 'direito ao corpo' e estes estão "encapsulados como direitos de personalidade". Portanto, quando são analisadas as questões pertinentes a construção indentitária no direito brasileiro, percebe-se o quão influem nesse processo as "experiências sociais, culturais, políticas e ideológicas" das quais cada individuo traz consigo em sua história de vida (FACHIN, 2014, p. 37).

\section{Direitos da personalidade: a autonomia privada na esfera civil e dignidade da pessoa trans no direito brasileiro}

Os direitos da personalidade são provenientes de uma construção histórica marcados por injustiças sociais e muita luta, isso porque, segundo as lições de Schreiber (2013, p. 05) esses direitos são considerados essenciais à condição humana. Na esteira da história, a Declaração Universal dos Direitos Humanos de 1948 foi um importante catalisador para o reconhecimento e 
proteção dos direitos da personalidade, ainda, encontrando garantia constitucional, anos depois, na Carta Magna brasileira, na qual tem entre os fundamentos da República a defesa da dignidade da pessoa humana, conforme previsto no artigo $1^{\circ}$, III.

A dignidade da pessoa humana, tal qual como adotada pela Carta Constitucional Brasileira, é o núcleo do qual são derivados todos os demais direitos e garantias fundamentais do ser humano. Para tanto, é possível afirmar que a dignidade é a pedra de toque fundamental dos direitos humanos. Ainda, nas palavras do Sarlet sobre o tema:

Temos por dignidade da pessoa humana a qualidade intrínseca e distintiva de cada ser humano que o faz merecedor do mesmo respeito e consideração por parte do Estado e da comunidade, implicando, neste sentido, um complexo de direitos e deveres fundamentais que assegurem a pessoa tanto contra todo e qualquer ato de cunho degradante e desumano, como venham a lhe garantir as condições existenciais mínimas para uma vida saudável, além de propiciar e promover sua participação ativa corresponsável nos destinos da própria existência e da vida em comunhão dos demais seres humanos (2001, p. 60).

A consagração da dignidade humana no mundo, bem como a sua incorporação à Constituição Brasileira de 1988 (CF/88), de acordo com Scrheiber (2013, p. 10) modificaram as perspectivas do direito civil, influenciando na construção de uma instrumentalização legal voltada ao campo da personalidade. Ainda, de acordo com o mesmo autor, o rol desses direitos não é taxativo, mas, sim, pode ser considerado um campo aberto e em constante evolução. Insta frisar que, o princípio da dignidade da pessoa humana é considerado o núcleo de força das demais garantias constitucionais, ou seja, desse centro derivam todos os outros direitos porque se tem nela a perspectiva axiológica das constituições.

Destarte, primeiramente, faz-se necessária a construção de um arcabouço teórico a respeito do que seria o nome e gênero para o direito civil brasileiro. Quando se analisa o capítulo dedicado aos direitos da personalidade no Código Civil de 2002, constata-se que somente foram abarcados formalmente 05 (cinco) garantias: o direito ao corpo, o direito ao nome, o direito à honra, o direito à imagem e o direito à privacidade. Para tanto, percebe-se que o Direito à identidade pessoal não encontra guarida 
expressa no referido Código (SCHREIBER, 2013, p. 15).

No entanto, a garantia de tutela ao direito à identidade pessoal ocorre por ressonância do artigo $1^{\circ}$, inciso III da $\mathrm{CF} / 88$, bem como esse instituto tem por núcleo magnético o Direito ao nome, o que sugere que esse arquétipo normativo social é considerado elemento de individualização do indivíduo, formando o sistema basilar do direito à identidade. Ainda, segundo Moraes (2010, p. 155): "É, então, o nome, um 'misto de direito e de obrigação', sem que uma dessas instâncias possa superar a outra: o direito da personalidade deve conviver com o interesse social, intrínseco na ideia de obrigação".

Nesta senda, Amorim (2003, p. 08) citado por Fachin (2014, p. 40) trouxe a seguinte classificação para o Direito ao nome:

A melhor doutrina atribui ao nome a natureza jurídica de direito de personalidade, na medida em que, como sinal verbal ou mesmo marca do indivíduo, o identifica dentro da sociedade e da própria família e é capaz de ser tutelado erga omnes. A lei assegura o direito ao nome, assim como seu registro em local adequado, obedecidas as formalidades, criando a particularização da pessoa, no mundo jurídico. Ele faz, pois, parte integrante da personalidade (grifo nosso).
28

Continuando, para Pereira (2004), o nome é um elemento designativo e fator de suma importância social, logo, ele integra a personalidade. Nesse sentido, ainda de acordo com os ensinamentos de Fachin (2014, p. 40), por estar inserido neste rol, existem características inerentes a este instituto, entre as quais estão "a obrigatoriedade, a indisponibilidade, a exclusividade, a imprescritibilidade, a inalienabilidade, a não-cessibilidade, a extracomercialidade, $\mathrm{a}$ inexpropriabilidade, a intransmissibilidade , a irrenunciabilidade e a imutabilidade".

No que se refere ao quesito da imutabilidade, o qual tem especial importância para o presente trabalho, cabe salientar que a Lei que rege os Registros Públicos, trata em seu artigo 58 do instituto 'Nome' e é anterior a Carta Magna Brasileira. Porquanto, de acordo com Camargo (2013, p. 225) “por questões de ordem pública, o legislador tornou o nome imutável, declarando ser de interesse social a manutenção do nome pelo individuo [...] elementar para a segurança jurídica”. No entanto, a melhor doutrina ensina que não há espaço para constituição de direitos ou 
institutos absolutos, visto que o viés absoluto traria prejuízos imensos aos direitos fundamentais, como por exemplo, o cerceamento do chamado "Princípio da Convivência das Liberdades", conforme leciona Moraes (2003, p. 61):

\begin{abstract}
Os direitos e garantias fundamentais consagrados pela Constituição Federal, portanto, não são ilimitados, uma vez que encontram seus limites nos demais direitos igualmente consagrados pela Carta Magna (Princípio da relatividade ou convivência das liberdades públicas). Desta forma, quando houver conflito entre dois ou mais direitos ou garantias fundamentais, o intérprete deve utilizar-se do princípio da concordância prática ou da harmonização de forma a coordenar e combinar os bens jurídicos em conflito, evitando o sacrifício total de uns em relação aos outros, realizando uma redução proporcional do âmbito de alcance de cada qual (contradição dos princípios), sempre em busca do verdadeiro significado da norma e da harmonia do texto constitucional com sua finalidade precípua.
\end{abstract}

Outrossim, conforme as evoluções sociais e legiferantes no país, a dignidade da pessoa humana tornou-se uma "diretriz máxima" da função estatal, assim, reconheceu-se entre o compasso da doutrina e jurisprudência brasileira, a relatividade das garantias fundamentais, dentre as quais pode-se citar a relativização da mudança do nome na própria legislação, haja vista que tanto o Código Civil, na matéria de direito de família, quanto a Lei de Registros Públicos, que prevê possibilidade de mudança de nome nas hipóteses de prenome ridículo, ou de integração de apelido notório, por exemplo (FACHIN, 2014, p. 41).

Infere-se, dessa forma, que o nome não apenas identifica, mais individualiza e concretiza um direito da personalidade perante sociedade e Estado, qual seja, o primeiro passo para garantia da autodeterminação corporal e social, quando não importe prejuízos a terceiros. Ainda, nas palavras do mesmo autor em foco, o nome é "elemento constitutivo para formação da identidade pessoal" carregando uma importante função social consigo (FACHIN, 2014, p. 41).

Nesse interim, atribui-se outro aspecto ao 'Nome' quanto a constituição do individuo, o direito à integridade psíquica deste, o qual também está englobado pelo rol aberto dos direitos da personalidade. Logo, preceituam Gagliano e Pamplona Filho (2014, p. 186) acerca do tema: "Conceituam-se os direitos da personalidade aqueles que têm por objeto os atributos físicos, 
psíquicos e morais da pessoa em si e em suas projeções sociais". Assim, tais direitos confluem para a proteção do homem e sua condição humana, bem como, tem-se que a proteção à integridade psicofísica faz parte dos direitos que estão abarcados pelo princípio da dignidade humana:

$\mathrm{Na}$ esfera cível, no entanto, a integridade psicofísica vem servindo para garantir numerosos direitos da personalidade (vida, nome, imagem, honra, privacidade, corpo, identidade pessoal), instituindo hoje o que se poderia entender como um "amplíssimo direito à saúde", compreendida como completo bem-estar psicofísico e social. (MORAES, 2016, p. 96) (grifo nosso).

Quanto ao gênero dentro do direito brasileiro, faz-se necessário estabelecer uma reflexão acerca do papel da identidade atribuída unilateralmente à pessoa natural ao nascer, quando questões como gênero e sexualidade são desconsiderados, reduzindo-se ao enquadramento binário: feminino ou masculino. Nesse sentido, Butler (2003, p. 46) ensina que:

O deslocamento estratégico dessa relação binária [...] pressupõe que a produção das categorias de feminino e masculino, mulher e homem, ocorra igualmente no interior da estrutura binária. [...] Foucault sugere que a categoria de sexo, anterior a qualquer caracterização da diferença sexual, é ela própria construída por via de um modo de sexualidade historicamente específico. Ao postular o "sexo" como "causa" da experiência sexuais, do comportamento e do desejo a produção tática da categorização descontínua e binária do sexo oculta os objetivos estratégicos do próprio aparato de produção.

Corroborando para este estamento, Bolesina e Gervasoni (2018, p. 72) trazem a ideia de que os binarismos foram fundados para fins organizacionais, no entanto, sua prática deliberada operou não apenas uma oposição entre os sexos biológicos, mas, sim, verdadeiras dicotomias históricosociais. Ainda, de acordo com os mesmos autores, esta fixação arbitraria dos gêneros ao nascimento é, também, reflexo de sociedades patriarcais que tendem sempre a orbitar pelo centro de poder masculino. Por fim, este processo tem por resultado uma força de homogeneização, a qual tende por uma normalização desse processo binário, acarretando, por conseguinte, a naturalização dele.

Eis aqui o ponto crucial, o poder da naturalização das identidades, que subjugam as diferenças e reduzem a complexidade dos atributos que formam a identidade humana, que levam a aceitação social, em determinados 
níveis, de práticas discriminatórias e de não enquadramento na sociedade. Destarte, deve-se entender gênero como uma construção social, cultural e comportamental, a qual deve ser observada pelo viés do princípio da liberdade individual numa perspectiva de livre exercício da vida privada, assim, tal qual define Moraes (2016, p. 108): “O princípio da liberdade individual consubstancia-se, numa perspectiva de privacidade, intimidade e livre exercício da vida privada. Liberdade significa, [...] poder realizar [...] as próprias escolhas individuais $[\ldots]$ exercendo-o como melhor convier".

Ainda, conforme lição de Fachin (2014, p. 45) a perspectiva histórica a cerca do conceito de gênero encontram raízes nos movimentos feministas que visavam contrapor o biologismo dos sexos, levando em conta o resultado de uma construção baseada numa realidade social patriarcal. Dentro desta acepção, Andrade (2015, p. 15) elucida:

Por esta razão, a construção da identidade sexual é consequência da construção da subjetividade da pessoa, no exercício de sua autonomia ético-existencial, do direito ao autodesenvolvimento que se firma em dois pilares básicos - o respeito à dignidade da pessoa humana e o direito de liberdade geral de ação, culminando, portanto, no direito à autodeterminação da identidade de gênero.

Assim, a identidade de gênero é um processo de se fazer o corpo feminino ou masculino, sendo os atributos de qualificação moldados pelas características intrínsecas e carregadas de significado cultural. Por conseguinte, tem-se, diante de todos os desenvolvimentos citados, uma construção "funcional e dinâmica do direito à identidade pessoal, voltada a promover e garantir uma fidedigna apresentação da pessoa humana em sua inimitável singularidade" (SCHREIBER, 2013, p. 216). Seguindo o pensamento do mesmo autor, o direito à identidade permite que cada individuo desenvolva e se permita encontrar sua individualidade numa sociedade que tendia uma planificação de corpos e pensamentos.

Em outras palavras, este instituto vislumbra como uma centelha de permissão para a autenticidade do ser humano em sua plenitude permitindo uma consonância com as evoluções sociais, tal qual a máxima aristotélica e que se encontra premiada, hermeneuticamente, no rol das garantias fundamentais tutelados pela Carta 
Magna brasileira. Dessa forma, "dignidade e responsabilidade se conjugam com a liberdade" do individuo trans em encontrar-se dentro de suas singularidades humanas e que resultem num processo de respeito, garantia de felicidade e qualidade de vida.

\section{O direito à autodeterminação corporal no brasil: uma garantia de cidadania à pessoa transgênero}

Quando se pensa em corpos e regulações jurídicas, é inegável as profundas influências históricas e religiosas sofridas pelo tema no decorrer da história humana. Logo, encontram-se na locução "direito ao corpo" uma confluência complexa de sentidos jurídicos e psíquico sociais, os quais revelam que, hoje, o corpo humano está para "atender a realização da própria pessoa e não aos interesses de qualquer entidade abstrata, como Igreja, família ou Estado" (SCHREIBER, 2013, p. 32).

Analisando o Código Civil brasileiro, em seu artigo 13, foram assentados critérios sobre a disposição do próprio corpo, tendo três características básicas endereçadas ao referido dispositivo, as quais podem ser listadas abaixo conforme lição de Schreiber (2013, p. 34):

(i) primeiro, ao autorizar qualquer disposição do próprio corpo por "exigência médica", o art. 13 parece elevar a recomendação clínica a um patamar superior a qualquer avaliação ética ou jurídica;

(ii) segundo, ao vedar a disposição do próprio corpo que importe "diminuição permanente da integridade física", o art. 13 sugere, a contrario sensu, que estariam autorizadas reduções não permanentes, o que se mostra extremamente perigoso;

(iii) terceiro, o art. 13 alude à noção de "bons costumes", ideia vaga e imprecisa, que pode causar serias dificuldades em um terreno que sofre decisiva influencia de inovações tecnológicas e científicas.

Diante do explanado, oportuno voltar a atenção para a correlação entre o artigo 13 do Código Civil, a cirurgia de redesignação sexual e a supervaloração da verdade médica. Isso porque, segundo Schreiber (2013, p. 44) as intervenções médicas quanto a mudança sexual, de acordo com a Resolução do CFM $1.955 / 2010$ em conjunto com o dispositivo do Código Civil permitem a cirurgia no Brasil, no entanto, impõe-se o dever de atender ao requisito da exigência médica para tal. Ainda, de acordo com o mesmo autor, "o resultado pode parecer progressista, já que se permite $[\ldots]$ a cirurgia. [...]. A 
abordagem, contudo, é a mais retrograda possível", visto o viés patológico que carrega consigo tais elementos para a autonomia da autodeterminação corporal.

Adiante, muitos foram os embates jurídicos entre as pessoas trans, que buscavam obter o direito sobre o próprio corpo, e as decisões provenientes do judiciário brasileiro quanto ao tema. Isso porque, a questão da redesignação sexual, em primeiro momento, ficou estrita a esfera judicial contenciosa, quando em décadas passadas imperava o conservadorismo dos julgados, tal qual percebe-se através de decisão proferida pelo Tribunal de Justiça do Rio de Janeiro, no ano de 1993:

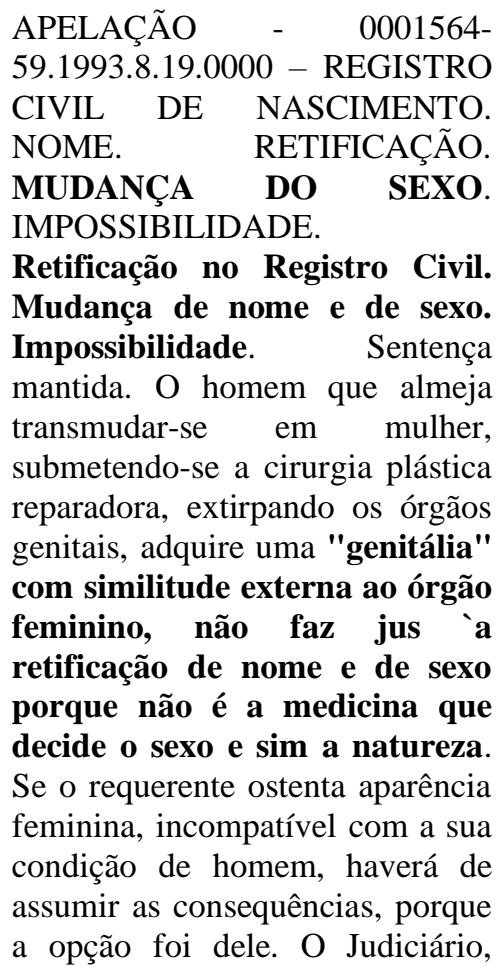

ainda que em procedimento de jurisdição voluntária, não pode acolher tal pretensão, eis que a extração do pênis e a abertura de uma cavidade similar a uma neovagina não tem o condão de fazer do homem, mulher. Quem nasce homem ou mulher, morre como nasceu. Genitália similar não é autentica. Autêntico é o homem ser do sexo masculino e a mulher do feminino, a toda evidência. (MSL). TJRJ, APELAÇÃO CÍVEL, 1993.001.06617, Des (a). GERALDO BATISTA Julgamento: 18/03/1997 OITAVA CÂMARA CÍVEL. (grifo nosso)

Como infere-se pelo julgado acima, muitas foram as decisões judiciais de cunho moralizador e permeadas por concepções tradicionalistas homogeneizantes. Assim, a mudança deste panorama no Brasil, iniciou-se com as modificações operadas pelo CFM e do Sistema Único de Saúde - SUS, ambos impulsionados por fortes modificações internacionais, citadas em capítulo anterior. Ademais, dentro da acepção de direito ao próprio corpo, segundo os ensinamentos de Fachin (2014, p. 54) a qualidade de vida da pessoa trans está intrinsecamente ligada a "instituição de uma identidade própria”.

Nesse sentido, decisões judiciais foram evoluindo no compasso das mudanças sociais e das novas normas introduzidas pelo CFM e pelo SUS, 
fornecendo estruturas mais condizentes

com o caráter constitucional brasileiro, em defesa da dignidade da pessoa humana. De acordo com Schreiber (2013, p. 46) “o direito ao próprio corpo não deve ser protegido como uma exigência social de ordem e segurança, mas como um instrumento de realização da pessoa". Nesta senda, uma decisão que propiciou significativas mudanças dos posicionamentos, dentro do judiciário brasileiro, ocorreu no ano de 2002, através de julgado do Superior Tribunal de Justiça (STJ) sobre cirurgias de redesignação sexual, sob relatoria da ministra Nancy Andrighi, por consequência, diante da importância dessa jurisprudência, faz-se pertinente transcreve-la a seguir:

DIREITO CIVIL. RECURSO ESPECIAL. TRANSEXUAL SUBMETIDO À CIRURGIA DE REDESIGNAÇÃO SEXUAL. ALTERAÇÃO DO PRENOME E DESIGNATIVO DE SEXO. PRINCÍPIO DA DIGNIDADE DA PESSOA HUMANA. - Sob a perspectiva dos princípios da Bioética, de beneficência, autonomia e justiça, a dignidade da pessoa humana deve ser resguardada, em um âmbito de tolerância, para que a mitigação do sofrimento humano possa ser o sustentáculo de decisões judiciais, no sentido de salvaguardar o bem supremo e foco principal do Direito: o ser humano em sua integridade física, psicológica, socioambiental e ético-espiritual.
- A afirmação da identidade sexual, compreendida pela identidade humana, encerra a realização da dignidade, no que tange à possibilidade de expressar todos os atributos e características do gênero imanente a cada pessoa. Para o transexual, ter uma vida digna importa em ver reconhecida a sua identidade sexual, sob a ótica psicossocial, a refletir a verdade real por ele vivenciada e que se reflete na sociedade.

[...]

- Assegurar ao transexual o exercício pleno de sua verdadeira identidade sexual consolida, sobretudo, o princípio constitucional da dignidade da pessoa humana, cuja tutela consiste em promover o desenvolvimento do ser humano sob todos os aspectos, garantindo que ele não seja desrespeitado tampouco violentado em sua integridade psicofísica. Poderá, dessa forma, o redesignado exercer, em amplitude, seus direitos civis, sem restrições de cunho discriminatório ou de intolerância, alçando sua autonomia privada em patamar de igualdade para com os demais integrantes da vida civil. A liberdade se refletirá na seara doméstica, profissional e social do recorrente, que terá, após longos anos de sofrimentos, constrangimentos, frustrações e dissabores, enfim, uma vida plena e digna. (...) Recurso especial provido. (REsp 1.008.398/SP, Rel. Ministra Nancy Andrighi, Terceira Turma, julgado em 15.10.2009, DJe 18.11.2009) (grifo nosso)

Todavia, o reconhecimento e asseguramento da cirurgia de redesignação à pessoa trans, em muitos casos, deixou de ser um direito e passou a ser uma "obrigatoriedade" no sentido 
de se obter as retificações devidas nos documentos públicos, conforme decisão do Tribunal de Justiça de Sergipe, transcrita a seguir:

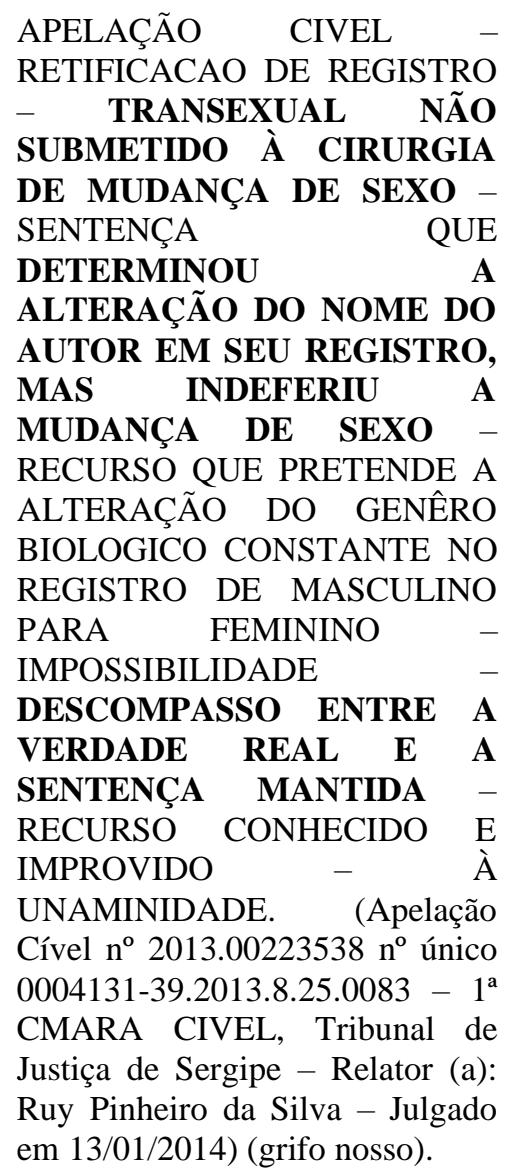

Outrossim, diante deste último julgado, percebe-se que a imposição da cirurgia de mudança de sexo como condição para retificação do Registro Civil configuraria ato de "infração ao direito ao próprio corpo" (FACHIN, p. 55). Isso porque, como qualquer ato cirúrgico, existem os riscos que devem ser considerados, bem como, por se tratar
35

de um procedimento extremamente invasivo e irreversível. Aqui, faz-se pertinente relembrar os ensinamentos de Pontes e Saraiva (2017, p. 85) quando afirmam que o gênero não se confunde com orientação sexual, visto que a designação do sexo ao nascer, possui um caráter eminentemente biológico, ou seja, desconsideram-se componentes culturais, sociológicos, psicológicos e de outras ordens que serão essenciais para a construção da personalidade de cada ser humano.

Dessa forma, a identidade da pessoa trans faz parte de uma construção oriunda do sentimento de pertencimento cultural e social a determinados padrões estéticos ou comportamentais considerados próprio ao sexo oposto da pessoa trans. Em verdade, quando os seres humanos vão sendo moldados paralelamente às transformações sociais dos elementos socionormativos que os compõem, por conseguinte, "o gênero não poderia ser simplesmente concebido como a inscrição cultural que significa um sexo previamente dado". Nesse sentido, quando uma pessoa se reconhece transgênero não significa dizer que há um desejo eminente de redesignação sexual, pois: 
Gênero seria um processo contextual e contingencial, ponto de convergência de fenômenos históricos e culturais localizados e reais, não atrelado a um ser substantivo fundacional, ou seja, no lugar de gênero vinculado ao sujeito, Judith Butler preconiza ser o gênero o efeito de certas relações sociais, políticas, históricas e culturais (FREITAS, 2016, p. 233).

E vai além, nem mesmo é possível determinar que a pessoas trans tem ou terão atração sexual por pessoas do mesmo sexo, porquanto, reflete-se a existência de um conflito natural de identidade - em seu sentido amplo de reconhecimento e pertencimento - com o gênero, biologicamente falando. Porquanto, de acordo com Fachin (2014, p. 56):

Fica evidente, portanto, que a exigência da cirurgia de redesignação sexual vai de encontra à eleição da pessoa transexual, de modo que cabe exclusivamente a ela, compreendendo todas as suas implicações, realizá-la ou não. Impor um pré- requisito a um direito fundamental mutila, em nosso ver, a própria definição de direitos fundamentais e direitos de personalidade, que se baseiam na ideia de inerência ao ser humano.

Destarte, do ponto de vista da Carta Magna, a qual tem por epicentro axiológico a dignidade da pessoa humana, não era razoável ter por condição a realização da cirurgia de redesignação como condição para retificação do nome e gênero no RCPN. Assim, no bojo destas mudanças jurídicas, veio a Ação direta de Inconstitucionalidade (ADI) de $\mathrm{n}^{\circ}$ 4.275/DF, impetrada pelo Ministério Publico Federal (MPF), quando pretendeu-se viabilizar aos transgêneros a alteração do prenome e sexo no documento público independente de realização de cirurgia de transgenitalização. Essa decisão configurou-se em um divisor de águas visto a desnecessidade de comprovação de readequação sexual para alteração do RCPN, bem como, deixou-se a senda do contencioso, passando a integrar a esfera administrativa com a permissão para a retificação direta pelos Cartórios de Registro Civil de Pessoa Natural, bastando o cumprimento de determinados requisitos, os quais serão abordados no próximo capítulo.

Direito à identidade e a extrajucialização do nome e gênero da pessoa trans: análise dos dados dos cartórios de registro de pessoa natural da cidade de Recife/PE 
A Ação Direta de Inconstitucionalidade (ADI) 4275, foi um importante instrumento de garantia de dignidade e adequação do judiciário brasileiro diante das demandas da população trans. Cronologicamente falando, no ano de 2009, o Ministério Publico Federal (MPF) por meio da Procuradoria Geral da Republica, impetrou tal ação buscando, dentro da hermenêutica constitucional, dar interpretação conforme a Constituição ao artigo 58 da Lei de n. ${ }^{\circ}$ 6.015/73 - Lei de Registros Públicos, na redação conferida pela Lei n. ${ }^{\circ}$ 9.708/98. A peça foi elaborada pela Procuradora da República e Doutora Deborah Macedo Duprat de Britto Pereira, na qual visou reconhecimento aos transexuais, independente de comprovação de cirurgia de transgenitalização, ao direito a alteração do nome e sexo/gênero no RCPN.

Nesta senda, a decisão final para esta ADI apenas ocorreu no ano de 2018, passados 09 (nove) longos anos desde sua propositura, quando decidiu o STF pela procedência do pedido requisitada pelo MPF, como, assim, percebe-se pela transcrição da ementa abaixo:
37

AÇÃO DIRETA DE INCONSTITUCIONALIDADE. DIREITO CONSTITUCIONAL E REGISTRAL. PESSOA TRANSGÊNERO.

ALTERAÇÃO DO PRENOME E DO SEXO NO REGISTRO CIVIL. POSSIBILIDADE. DIREITO AO NOME, AO RECONHECIMENTO DA PERSONALIDADE JURÍDICA, À LIBERDADE PESSOAL, À HONRA E À DIGNIDADE. INEXIGIBILIDADE DE CIRURGIA DE TRANSGENITALIZAÇÃO OU DA REALIZAÇÃO DE TRATAMENTOS HORMONAIS OU PATOLOGIZANTES.

1. O direito à igualdade sem discriminações abrange a identidade ou expressão de gênero.

2. A identidade de gênero é manifestação da própria personalidade da pessoa humana e, como tal, cabe ao Estado apenas o papel de reconhecê-la, nunca de constituíla.

3. A pessoa transgênero que comprove sua identidade de gênero dissonante daquela que lhe foi designada ao nascer por auto identificação firmada em declaração escrita desta sua vontade dispõe do direito fundamental subjetivo à alteração do prenome e da classificação de gênero no registro civil pela via administrativa ou judicial, independentemente de procedimento cirúrgico e laudos de terceiros, por se tratar de tema relativo ao direito fundamental ao livre desenvolvimento da personalidade.

4. Ação direta julgada procedente. ADI 4275, Relator(a): Min. MARCO AURÉLIO, Relator(a) p/ Acórdão: Min. EDSON FACHIN, Tribunal Pleno, julgado em 01/03/2018, PROCESSO ELETRÔNICO DJe-045 DIVULG 06-03-2019 PUBLIC 07-03-2019) (grifo nosso). 


\section{Quanto a interpretação do artigo}

58 da Lei de Registros Públicos, faz-se pertinente aborda-lo aqui para melhor entendimento. Dessa forma, dispõe ele que: “Art. 58. O prenome será definitivo, admitindo-se, todavia, a substituição por apelidos públicos e notórios (redação dada pela Lei no 9.708 de 1998)", logo, tem-se a questão da situação vivenciada pelos transexuais que eram obrigados a sofrer constrangimentos e discriminações diante do descompasso entre o nome social e sua identidade.

Consubstanciando esse tema, tem-se o seguinte acordão, anterior a ADI 4275/09, no qual apresenta o fundamento de que não seria a cirurgia a força concessiva da condição transexual, ou melhor, seria apenas mais um passo para construção da identidade pessoal. Destarte, como já visto, o direito à identidade de gênero encontra guarida nos direitos da personalidade e de dignidade da pessoa humana, assim, justifica-se, independente de cirurgia, a modificação no RCPN, desde que obedecidos determinados critérios que estão postos em redação elaborada pelo Conselho Nacional de Justiça (CNJ).
38

Além disso, haja posta a adequação com a realidade constitucional brasileira, outro fator que contribuiu positivamente foram as legislações internacionais pertinentes aos Direitos Humanos, em especial o Pacto de San Jose da Costa Rica, no qual subscreve direitos ao sistema legal pátrio tais como o direito ao nome (artigo 18), reconhecimento à liberdade pessoal (artigo $\left.7^{\circ}, 1\right)$ e à dignidade (artigo 11, 2).

Adiante, em junho de 2018, o CNJ publicou o Provimento $\mathrm{n}^{\mathrm{o}} 73$, no qual trouxe regulamentação da decisão proferida anteriormente pelo STF, relacionada a alteração e averbação do prenome e do gênero nos assentos de nascimento e casamento da pessoa transgênero, sendo esse feito realizado diretamente pelos Cartórios Brasileiros. Ainda, a respeito da norma supramencionada, vale a pena descrever alguns importantes pontos, por exemplo, em seu artigo $2^{\circ}$, é garantido que toda pessoa maior de 18 anos completos e capaz de praticar atos da vida civil, poderá requerer diretamente ao oficio de RCPN a alteração e averbação do prenome e gênero em sua certidão de nascimento ou casamento, a depender do estado civil da pessoa em questão. 
Seguindo, no mesmo artigo, essa alteração poderá abranger ou excluir agnomes indicativos de gênero ou descendência $\left(\S 1^{\circ}\right)$. Ainda, tal procedimento poderá ser realizado tanto no local original de assentamento do registro ou até mesmo em cartório distinto, no entanto, o requerente irá arcar com as expensas referentes à averbação pela Central de Informações do Registro (parágrafo único). Outro ponto, de acordo com o artigo $4^{\circ}$, a pessoa trans que requerer essa modificação deverá declarar e assinar ato de vontade perante o registrador do RCPN à livre escolha à adequação da identidade mediante averbação do prenome, do gênero ou de ambos. Já no $\S 1^{\circ}$ do mesmo artigo, o provimento destaca que não é mais necessária autorização judicial para tal ato.

Além disso, no $\$ 6^{\circ}$ do supracitado artigo, são listados os documentos necessários para a realização do trâmite administrativo, já o $\S 7^{\circ}$ traz como opção da pessoa trans ajuntar laudos médicos ou pareceres psicológicos sobre sua condição trans. Importa salientar que, a todo esse processo é garantido o sigilo, assim como não constarão na folha de Certidão a averbação de tal modificação, logo, tal registro será gravado apenas nos livros arquivados nos Cartórios.

No que se refere ao $\S 6^{\circ}$ do artigo $4^{\circ}$ do Provimento $n^{\circ} 73 / 2018$, a pessoa trans deve apresentar, obrigatoriamente, no mínimo, 17 (dezessete) documentos, dos quais 07 (sete) são certidões dos distribuidores cível e criminal, execução criminal, dos tabelionatos de protestos do local de residência, bem como, certidões das Justiças Eleitoral, do Trabalho e Militar. Para a emissão de cada uma dessas certidões há um custo. Ocorre que, nas demais hipóteses de mudanças de nome, não motivadas pela modificação do gênero, as exigências documentais não são extensas e/ou dispendiosas, para tanto, cita-se a possibilidade de incluir os sobrenomes dos cônjuges em razão do casamento, ou a exclusão em decorrência do divórcio (ambas feitas em cartórios). Vale a pena mencionar outro exemplo que dispensa extensa documentação, que diz respeito ao Provimento ${ }^{\circ}$ 63/2017, o qual permite o reconhecimento extrajudicial da paternidade/maternidade socioafetiva com a consequente adição do sobrenome do pai ou mãe socioafetivo. Não há dúvidas que o atual 
sistema jurídico de mudança de nome/sobrenome apresenta fragilidades, e desrespeita a necessária equidade que o tema merece, diante do tratamento diferenciado ora ilustrado, que impõem exigências extensas e injustificadas para determinados casos de mudança de nome, enquanto para outros os procedimentos são mais simples e menos onerosos.

Quanto às proibições, existem dois pontos que merecem abordagem, sendo o primeiro: não é permitida a modificação de nomes de família e não pode ensejar identidade de prenome com outro membro da família ( $§ 2^{\circ}$, art. 2 ); e o segundo ponto, trata dos processos judiciais anteriores em aberto que tenham por objeto a alteração pretendida, logo, a pessoa trans deverá declarar a inexistência de processos judiciais sobre o tema ou comprovar o arquivamento do feito judicial em caso positivo $\left(\S \S 4^{\circ}\right.$ e $5^{\circ}$, art. $\left.4^{\circ}\right)$.

Desde a vigência do presente sistema regulamentar proferido pelo CNJ - Provimento $n^{\circ} 73 / 2018$, os 15 (quinze) Cartórios de Registro de Pessoas Naturais da cidade do Recife/PE passaram a receber pessoas trans para a voluntária retificação e averbação do nome e sexo correspondentes a sua identidade de gênero nas respectivas certidões. Insta frisar que, os dados que serão aqui apresentados, objeto dessa pesquisa, foram obtidos de forma regulamentar através da autorização da Corregedoria Auxiliar dos Serviços Notariais e de Registro da Capital do Poder Judiciário de Pernambuco, bem como foram tratados de maneira cientifica e sigilosa.

Dessa maneira, diante dos dados levantados, cerca de 2/3 (dois terços) dos Cartórios Extrajudiciais enviaram os dados solicitados, fato esse que corresponde a $75 \%$ (setenta e cinco por cento) do número total. Porquanto, foi possível constatar que cerca de 108 (cento e oito) pessoas trans procuraram os serviços cartorários recifenses durante os primeiros 08 (oito) meses contados da vigência do supracitado Provimento do CNJ. Ainda, foi possível constatar que a maioria dos interessados possuem o estado civil de solteiro, dado que correspondente acerca de 96,3\% (noventa e três vírgula três por cento) do total. Todas as pessoas trans solicitaram, além da mudança de gênero, também, a alteração do prenome. 
Prosseguindo, no que diz respeito ao gênero selecionado, cerca de 45,37\% (quarenta e cinco vírgula trinta e sete por cento) optaram pelo gênero masculino, enquanto $54,63 \%$ (cinquenta e quatro vírgula sessenta e três por cento) mudaram o gênero para feminino. Importa ressaltar que, conforme já mencionado, a solicitação de mudança do nome e gênero somente pode ser requerida a partir dos 18 (dezoito) anos, para tanto, foram estabelecidas 05 (cinco) faixas etárias, quais sejam: faixa 01 - dos 18 a 27 anos; faixa 02 - 28 a 37 anos; faixa 03 - 38 a 47 anos; faixa 04 48 a 57 anos; e, por último, faixa $05-$ pessoas com idade igual ou superior a 58 anos.

Em continuidade, considerando as referidas faixas etárias, observa-se que o maior número de solicitações de mudança de gênero se encontra nas primeiras duas faixas, ou seja, a faixa 01 com $54,63 \%$ (cinquenta e quatro vírgula sessenta e três por cento) e a faixa 02 com $25,93 \%$ (vinte e cinco vírgula noventa e três por cento). Fato esse que implica dizer que, cada vez mais as pessoas jovens e trans tem optado por pela modificação extrajudicial, corroborando para o pensamento trazido por Araújo (2016, p. 257-258) de que, com a evolução do pensamento científico e cultural, a base conceitual tradicional do sexo não mais comporta as categorias predeterminadas pelo fenótipo.

Dessa forma, tem-se na perspectiva de implementação de direitos à intimidade e da autoafirmação dentro das relações da esfera privada, a realização da autonomia do individuo, o qual não precisa mais subjugar-se a longos processos contenciosos para um direito de complexidade fácil de ser solucionada. Afora isso, é preciso frisar que a identidade do individuo trans abrange sua personalidade, por conseguinte, segundo Bolesina e Gervasoni (2018, p. 67) "os caminhos a serem percorridos para a obtenção de uma definição jurídica mais atenta demandaria uma revisão de titulo: os 'direitos da personalidade' deveriam ser vistos como "direitos da identidade", a qual englobaria um projeto de definição existencial particular, viabilizando, assim, uma emancipação pessoal que objetive a identidade condigna.

Outrossim, Souza Santos (2003, p. 56) defendeu interessante tese de que o direito de ser igual sempre inferioriza, 
por consequência, deve-se, sempre, contemplar o direito de ser diferente sempre que a igualdade descaracterizar a identidade de cada individuo. Dessa forma, o direito à identidade pessoal nasce da urgência de ser tutelado pela "verdade pessoal", assim, o número de pessoas trans que tem optado pela modificação do prenome e gênero pela via cartorária tem demonstrado a materialização da verdade pessoal da pessoa trans a ter o seu direito garantido via Registros Públicos.

Ademais, é inaceitável numa sociedade que se guia pela plenitude das liberdades, conformar-se a existência de “cidadãos pela metade" (ARAÚJO, 2016, p. 259), os quais lutam pela normalidade de gênero, de serem incluídos e usufruírem dos direitos e deveres como qualquer cidadão brasileiro. Isso porque, não cabe ao Direito interferir nas escolhas de construção da personalidade, mas sim ser um viés condutor de efetivação de direitos. Portanto, oportuna as lições de Lira e Lando (2019, p. 50-51) quanto ao direito de ser trans e ter a compleitude de sua identidade garantida pelo Estado, numa sociedade democrática de direito, pois "deve-se defender a primazia da pluralidade e das liberdades" para que, assim, seja possível a todos e todas uma convivência harmoniosa e pacifica entre as diferenças da condição humana.

\section{Considerações finais}

Permite-se concluir que a identidade da pessoa trans faz parte de uma lenta construção cultural e social, os quais somados, resultam no reconhecimento da condição trans. No entanto, esse fato não determina, necessariamente, que pessoa transgêneros terão o desejo para a realização da cirurgia de redesignação sexual. Logo, constata-se nas decisões judiciais que implicavam a comprovação de tal ato médico, uma extrapolação do poder estatal para com a autonomia da vida privada destes indivíduos, bem como, um desrespeito à dignidade humana e sexual da pessoa trans.

Dessa forma, não cabe ao Direito interferir nas escolhas pessoais de construção da personalidade de cada um, visto também que são pertencentes à esfera privada e ao direito de se autodeterminar. Portanto, cabe ao estado, tanto em sua atuação política quanto jurídica, atuar como um viés 
condutor de garantias fundamentais, proporcionando, assim, meios para efetivação de direitos. Isso porque, numa sociedade democrática, na qual defendese a primazia da pluralidade e das liberdades, deve-se perseguir incansavelmente a defesa da convivência harmoniosa e pacífica das diferenças. Visto isso, tem-se que a dignidade das pessoas transexuais é transversal a institutos como autodeterminação e construção de identidade própria, os quais estão balizados pela tutela do princípio maior que é a dignidade da pessoa humana.

Ademais, na esteira das mudanças apresentadas, tem-se a certeza de que a identidade humana é única e está em constante desenvolvimento. Ante a tudo aqui exposto, a luta pelo reconhecimento de direitos essenciais de grupos sociais como os LGBTQI+, no Brasil, demonstra o quão são demoradas as mudanças sociopolíticas, bem como, fazem-se necessário, ainda, percorrer um longo caminho em se tratando de implementação de Direitos Fundamentais ligados à dignidade e cidadania plena. Além do mais, importa dizer que ainda são escassos os dados quanto a comunidade transgênero brasileira, carecendo de números oficiais para melhor precisão das informações, a exemplo da inclusão das pessoas trans em levantamentos censitários.

Por fim, é preciso dizer de forma contundente que ainda existe um fosso alarmante entre as últimas conquistas obtidas pela comunidade trans e a real efetivação destes direitos. Isso porque, persiste um quadro que se enerva a falta de informação com o obscurantismo de posicionamentos reacionários, hoje, impulsionados pela atual retórica política brasileira. Nesse sentido, para que seja possível superar o estigma de cidadãos pela metade, são necessários programas governamentais educacionais e políticas públicas voltados tanto ao grupo trans quanto a toda sociedade civil como forma de integração destas diferenças sociais, para que, assim, se possa realmente efetivar direitos como premissas básicas de dignidade humana e cidadanias plenas.

\section{Referências}

ANDRADE, Larissa (2015), Direito à identidade de gênero à luz da constitucionalização do Direito Civil: análise do Projeto de Lei Joao W. Nery 
(PL nº 5002/2013). (S.L.): Jusnavigandi. Disponível em

$<$

https://jus.com.br/artigos/40126/direito$\underline{\text { a-identidade-de-genero-a-luz-da- }}$ constitucionalizacao-do-direito-civilanalise-do-projeto-de-lei-joao-w-nerypl-n-5-002-2013 > Acesso em julho de 2019.

ARÁN, Márcia; MURTA, Daniela (2009), Do diagnóstico de transtorno de identidade de gênero às descrições da experiência da transexualidade: uma reflexão sobre gênero, tecnologia e saúde. Rio de Janeiro: Physis Revista de Saúde Coletiva, v.19, nº 01, p. 15-41. ARAÚJO, Jailton Macena de (2016), Pós-Gênero e Direitos Humanos: Aspectos Bioéticos do Processo de redesignação sexual em adolescentes transexuais. João Pessoa: Periódico Gênero e Direito, v. 05. no 01. p. 256281.

BENTO, Berenice; PELÚCIO, Larissa (2012), Despatologização do gênero: a politização das identidades abjetas. Florianópolis: Revista Estudos Feministas, v. 20, nº 02. p. 559-581.

BERGESCH, Vanessa; CHEMIN, Beatris Francisca (2009), A cirurgia de
Transgenitalização e a concretização dos direitos fundamentais. Rio Grande do Sul: Revista Destaques Acadêmicos, a. 01, no 02. p. 07-18.

BOLESINA, Iuri; GERVASONI, Tamiris Alessandra (2018). O direito à identidade pessoal no Brasil e seus fundamentos jurídicos na atualidade. Rio Grande do Sul: Revista Saber Humano, v. $08, \mathrm{n}^{\circ} 13$. p. 65-87.

BRASIL, Constituição da República Federativa do Brasil de 1988 (2012), Brasília: Senado Federal, Subsecretaria de Edições Técnicas.

Conselho Nacional de Justiça (2017), Provimento $\mathbf{n}^{\mathbf{0}} \mathbf{6 3}$ de 14/11/2017. Brasília. Disponível em: < https://atos.cnj.jus.br/atos/detalhar/atosnormativos?documento $=2525>$ Acesso em janeiro de 2020.

Conselho Nacional de Justiça (2018), Provimento $\mathbf{n}^{\mathbf{0}} \mathbf{7 3}$ de 26/06/2018. Brasília. Disponível em: < http://www.cnj.jus.br/busca-atos$\underline{\text { adm?documento }=3503}>$ Acesso em abril de 2019.

Supremo Tribunal Federal (2018), STF reconhece a Transgêneros possibilidade de alteração de registro civil sem mudança de sexo. Brasília. 
Disponível

em:

http://www.stf.jus.br/portal/cms/verNoti ciaDetalhe.asp?idConteudo $=371085>$

Acesso em abril de 2019.

BUTLER, Judith P (2003), Problemas de gênero: feminismo e subversão da identidade. Rio de Janeiro: Civilização Brasileira.

CAMARGO, Mateus Travaioli (2013), O princípio da Imutabilidade do Nome Civil e sua Flexibilização na Sociedade Contemporânea. São Paulo: Revista do Curso de Direito da Faculdade de Humanidades e Direito, v. 10, $\mathrm{n}^{\mathrm{o}}$ 10. p. 213-242.

CASTEL, Pierre-Henri (2001), Algumas Reflexões para estabelecer a cronologia do "fenômeno transexual" (1910-1995).

São Paulo: Revista Brasileira de História, v. 21, nº 41, p. 77-111, 2001.

COSTA, Welington O. de S. dos Anjos; CAMPELlO, Livia G. Bósio (2017), Patologização da Transexualidade sob a Ótica Jurídica: Mal (Des)necessário. Brasília: Revista de Gênero, Sexualidade e Direito, v. 03, $\mathrm{n}^{\mathrm{o}}$ 01, p. 108-123.

FÁBIO, André Cabette (2017), A Trajetória e as conquistas do Movimento LGBT brasileiro. (S.L.): Nexo Jornal Ltda. Disponível em < https://www.nexojornal.com.br/explicad o/2017/06/17/A-trajetória-e-asconquistas-do-movimento-LGBT-

$\underline{\text { brasileiro }}>$ Acesso em julho de 2019.

FACHIN, Luiz Edson (2014), O corpo do Registro no Registro do Corpo; Mudança de Nome e Sexo sem Cirurgia de Redesignação. São Paulo: Revista Brasileira de Direito Civil, v. 01, p. 3660.

FREITAS, Marcel de A (2016), Performances e Problemas de Gênero, Judith Butler. Rio de Janeiro: Civilização Brasileira.

GAGLIANO, Pablo Stolze; PAMPLONA FILHO, Rodolfo (2014), Novo curso de direito civil: parte geral. São Paulo: Saraiva, v. 01, $16^{\mathrm{a}}$ ed. LIRA, Roberta J. de L. Santos; LANDO, Giorge Andre (2019), O direito de ser trans para além da existência dos cidadãos pela metade. (S.L.): Prática Forense, ano III, no 31, p. 47-51. MORAES, Alexandre de (2003), Direito Constitucional. São Paulo: Atlas, $13^{a}$ ed.

MORAES, Maria Celina Bodin de (2016), Na medida da pessoa humana: estudos de direito civil-constitucional. Rio de Janeiro: Processo. 
PEREIRA, Caio Mário da Silva (2004), Instituições de Direito Civil. Rio de Janeiro: Forense, $20^{\mathrm{a}}$ ed.

PONTES, Ana C. A.; SARAIVA, Welligton C. (2017), Gênero, Ideologia e Percepções de Direitos Humanos no Ensino Básico. Brasília: Revista de Gênero, Sexualidade e Direito, v. 03, $\mathrm{n}^{\circ}$ 02, p. 80-99.

ROCHA, Luiz Augusto Castello Branco de Lacerda Marca da (2014), Os direitos da Personalidade e a Proteção ao transexual. Rio de Janeiro: Legis Augustus, v. 05, $\mathrm{n}^{\circ}$ 01, p. 01-21.

ROSSI, Amanda (2018), 'Monstro, prostituta, bichinha': como a Justiça condenou a $1^{\mathrm{a}}$ cirurgia de mudança de sexo do Brasil. São Paulo: Revista BBC Brasil. Disponível em < https://www.bbc.com/portuguese/geral$43561187>$ Acesso em agosto de 2019. SANTOS, Boaventura de Sousa (2003), Reconhecer para libertar: os caminhos do cosmopolitanismo multicultural. Rio de Janeiro: Civilização Brasileira.

SARLET, Ingo Wolfgang (2001), A eficácia dos direitos fundamentais. Porto Alegre: Livraria do Advogado.

SCHREIBER, Anderson (2013), Direitos da Personalidade. São Paulo: Atlas, $2^{\mathrm{a}}$ ed.
SOALHEIRO, Luiza H. M.;

CANÇADO, Paula O. M. A. (2017), Garota Dinamarquesa: Reflexão sobre o direito Fundamental à sexualidade. Brasília: Revista de Gênero, Sexualidade e Direito, v. 03, $\mathrm{n}^{\circ}$ 01, p. 01-16 